\title{
Follow up of New Zealand participants in British atmospheric nuclear weapons tests in the Pacific
}

\author{
Neil Pearce, Ian Prior, David Methven, Christine Culling, Stephen Marshall, Jackie Auld, \\ Gail de Boer, Peter Bethwaite
}

\begin{abstract}
Objective-To study the health of Royal New Zealand Navy personnel who participated in atmospheric nuclear weapons tests conducted by the United Kingdom at Malden Island and Christmas Island in 1957 and 1958.
\end{abstract}

Design-Blinded, controlled follow up of up to 30 years.

Setting-New Zealand.

Subjects - 528 Men known to have participated in the tests and a control group of 1504 men who were in the Royal New Zealand Navy during the same period but did not participate in the tests.

Main outcome measures-Mortality and incidence of cancer.

Results-Follow up for the period 1957-87 was $94 \%$ complete in test participants and $91 \%$ complete in the controls. There were $\mathbf{7 0}$ deaths among test participants and 179 deaths among controls, yielding a relative risk of $1.08(90 \%$ confidence interval 0.85 to $1.38, p=0.29)$. The relative risk of death from causes other than cancer was $0.96(0.71$ to $1.29, p=0.59)$ whereas the relative risk of death from cancer was $1.38(0.90$ to $2 \cdot 10, p=0.09)$ and of the incidence of cancer was $1.12(0.78$ to $1.60, p=0.29)$. For cancers other than haematological malignancies the relative risk was $1.14(0.69$ to $1.83, p=0.31)$ for mortality and $1.01(0.67$ to $1.50, p=0.48)$ for incidence. There were seven deaths from haematological cancers among test participants (relative risk $3 \cdot 25,90 \%$ confidence interval 1.12 to $9.64, p=0.02$ ), including four leukaemias $(5.58,1.04$ to $41 \cdot 6, p=0.03)$. The relative risk for incidence of haematological cancers was $1.94(0.74$ to $4.84, p=0.10)$ and that for leukaemia was $5.51(1.03$ to $41 \cdot 1, p=0.03)$. There were no cases of multiple myeloma in the test participants during the follow up period, but the expected number was only $\mathbf{0 \cdot 3}$.

Conclusions-Although the numbers are small, the findings for leukaemia are similar to those for British participants in the nuclear weapons test programme. Some leukaemias, and possibly some other haematological cancers, may have resulted from participation in this programme. There is little evidence of an increased risk for non-haematological cancers, and there is no evidence of an increased risk for causes of death other than cancer.

\section{Introduction}

In 1957 and 1958 Royal New Zealand Navy personnel participated in the series of atmospheric nuclear weapons tests (known as Operation Grapple) which were conducted by the United Kingdom at Malden Island and Christmas Island in the Pacific. The main task of HMNZS Pukaki and Rotoiti was to act as weather ships; secondary tasks included air-sea rescue, watching for submarines, monitoring thermal flashes, and water sampling.' The ships were stationed 35 to $280 \mathrm{~km}$ from ground zero throughout the series of tests.

In recent years concern has arisen regarding the possible health effects of participation in the tests. Some preliminary information was gathered by Dr Graham Gulbransen (a general practitioner in Auckland) and the Returned Services Association, and these groups subsequently asked the Ministry of Defence to fund an independent study. As a result, our research group was contacted by the Ministry of Defence, and after consultations with the Returned Services Association and Dr Gulbransen we agreed to undertake the study. ${ }^{2}$

\section{Subjects and methods}

SUBJECTS

The Royal New Zealand Navy personnel who participated in the tests (men in the Pukaki and Rotoiti) were identified from navy service record cards and annual navy lists of officers. (Some Royal New Zealand Air Force personnel provided back up for the tests and some New Zealand observers were aboard a British ship for one test, but the numbers involved were small and these groups were not included in the current study.) The controls comprised Royal New Zealand Navy personnel from three ships-HMNZS Kaniere, Royalist, and Lachlan - that were in service during 1957-8 but were not involved in Operation Grapple. As the test participants did not include any conscripts, these were excluded from the control group.

The information from the two other groups who had been collecting data on men who had served at Christmas and Malden Islands was used to check the completeness of the list of test participants obtained from the Ministry of Defence (table I). Overall, these

TABLE I-Sources of subjects and reasons for exclusions

\begin{tabular}{|c|c|c|c|}
\hline & \multicolumn{2}{|c|}{ Test participants } & \multirow[b]{2}{*}{ Control: } \\
\hline & $\begin{array}{l}\text { Already known } \\
\text { or not eligible }\end{array}$ & $\begin{array}{l}\text { Added to } \\
\text { study }\end{array}$ & \\
\hline Ministry of Defence lists & & 521 & 1512 \\
\hline Dr Gulbransen: & & 8 & \\
\hline Ineligible & 45 & & \\
\hline Eligibility not confirmed & 27 & & \\
\hline On Ministry of Defence list & 199 & & \\
\hline Returned Services Association list: & & 3 & \\
\hline Ineligible & 22 & & \\
\hline Eligibility not confirmed & 8 & & \\
\hline On Ministry of Defence list & 103 & & \\
\hline On Gulbransen list & 1 & & \\
\hline Media release: & & + & + \\
\hline On Gulbransen list & 1 & & \\
\hline Total & & 536 & 1516 \\
\hline Date of birth not known & & 8 & 12 \\
\hline Included in study & & 528 & 1504 \\
\hline
\end{tabular}


sources yielded the names of 323 men, of whom 57 were not eligible for the study (most of these had served with the Royal Navy rather than the Royal New Zealand Navy). Of the remaining 266 men, it was possible to verify that 235 were eligible for the study, and $224(95 \%)$ of these had already been identified from the Ministry of Defence list; 11 were added to the study. A further eight subjects responded to press statements issued by our group. Alternative sources thus identified only a further 15 test participants (including one who had died from heart disease and one registered as having lung cancer) and a further four controls (no deaths or cancer registrations), and it made little difference if these extra subjects were included or excluded. It was decided to include them so that the group of test participants could be as complete as possible.

These procedures identified 536 test participants and 1516 controls, but the dates of birth were not known for eight test participants and 12 controls, making ascertainment of vital state impossible (table I). Both ships and nearly 300 men participated in the first four nuclear weapons tests, and the subsequent five tests involved only the Pukaki with nearly 150 men. In total, 317 test participants $(60 \%)$ served on the Pukaki; 1079 controls (72\%) served on the Royalist. Thirteen participated in an unknown number of tests. The remaining 515 men attended an average of 3.6 tests, and 129 men (24\%) attended five or more tests.

The test participants and controls were similar with respect to the proportion of officers, year of enlistment, year of discharge, length of service, age at start of follow up, and length of follow up (table II). Information on cigarette smoking was obtained from those men who returned postal questionnaires: about $85 \%$ were current or ex-smokers (table II), but this is likely to be an underestimate because of attenuation by deaths among smokers. A figure of about $70 \%$ might have

TABLE II-Characteristics of test participants and controls. Figures are numbers (percentages)

\begin{tabular}{|c|c|c|}
\hline Characteristic & Test participants & Controls \\
\hline \multicolumn{3}{|l|}{ Rank: } \\
\hline Officers & $29(5)$ & $66(4)$ \\
\hline Other ranks & $499(95)$ & $1438(96)$ \\
\hline \multicolumn{3}{|c|}{ Year of enlistment: } \\
\hline $1900-29$ & $2<1)$ & 0 \\
\hline $1930-9$ & 51 & $16(1)$ \\
\hline $1940-9$ & 387 & $108(7)$ \\
\hline $1950-9$ & $419(79)$ & $1166,78)$ \\
\hline Unknown & $6412)$ & $214(14)$ \\
\hline Mean & 1953 & 1953 \\
\hline \multicolumn{3}{|l|}{ Year of discharge: } \\
\hline $1950-9$ & $84 \quad 16$ & $286(19)$ \\
\hline $1960-9$ & $3+365$ & $954(63)$ \\
\hline $1970-9$ & $69(13)$ & $172(11)$ \\
\hline $1980-9$ & 194 & 282 \\
\hline Unknown & $13(2)$ & $64(4)$ \\
\hline Mean & 1965 & 1964 \\
\hline \multicolumn{3}{|c|}{ Length of service (vears): } \\
\hline$<10$ & $246(47)$ & $779(52)$ \\
\hline $10-19$ & $145(28)$ & $356(24)$ \\
\hline $20-29$ & $51(10)$ & $122(8)$ \\
\hline$\geqslant 30$ & $18(3)$ & $19(1)$ \\
\hline Unknown & $68(13)$ & $228(15)$ \\
\hline Mean & $12 \cdot 2$ & $11 \cdot 1$ \\
\hline \multicolumn{3}{|c|}{ Age at start of follow up (years): } \\
\hline$<20$ & $156(30)$ & $427(28)$ \\
\hline $20-29$ & $257(49)$ & $732(49)$ \\
\hline $30-39$ & $97(18)$ & $292(19)$ \\
\hline$\geqslant 40$ & $18(3)$ & $53(4)$ \\
\hline Mean & $24 \cdot 8$ & $24 \cdot 9$ \\
\hline \multicolumn{3}{|c|}{ Length of follow up (years): } \\
\hline$<10$ & $56(11)$ & $184\langle 12\rangle$ \\
\hline $10-19$ & $26 \cdot 5$ & $73(5)$ \\
\hline $20-29$ & $131+25$ & $395(26)$ \\
\hline$\geqslant 30$ & $315(60)$ & $852(57)$ \\
\hline Mean & $26 \cdot 4$ & $25 \cdot 9$ \\
\hline \multicolumn{3}{|c|}{ Cigarette smoking: } \\
\hline Current & $129(25)$ & $314(21)$ \\
\hline Ex-smoker & $160<30$ & $473(31)$ \\
\hline Non-smoker & $60(11)$ & $147(10)$ \\
\hline Unknown & 179 & 570 \\
\hline
\end{tabular}

been expected on the basis of 1976 New Zealand census data for all men aged 45-49 (the average age of the study subjects in 1976) or about $80 \%$ for manual workers aged 45-49 (unpublished data). Thus the proportion of smokers was relatively high in both test participants and controls.

\section{FOLLOW UP}

It was attempted to follow all study subjects until 31 December 1987. All follow up was conducted blind. Information on the groups to which study subjects belonged was deleted during follow up. Deaths that had been coded according to earlier revisions of the International Classification of Diseases were recoded according to the ninth revision. ${ }^{+}$The New Zealand Cancer Registry has been more than $90 \%$ complete since the late 1950 s and virtually $100 \%$ complete since 1972. ${ }^{5}$ During 1985-7 there were some problems with registration of cancers diagnosed in private hospitals, but even so registration is believed to have been more than $90 \%$ complete. Apart from malignant melanoma, the cancer registry does not include skin cancers as these are almost always benign.

Subjects were recorded as having only one type of cancer, due to the difficulties of distinguishing multiple independent primary cancers from single tumours recurring at multiple sites. For men who had died of cancer their registrations were ignored, except in one case in which death was coded as due to a tumour of unspecified site and more detailed information was obtained from the cancer registration. For men in whom cancer had been diagnosed but who had not died of cancer, the site of the cancer and date of diagnosis was recorded from the cancer registry.

A postal questionnaire was used to ascertain whether those men who were not known to have died during 1957-87 were alive and resident in New Zealand as of 31 December 1987. When it was not possible to establish contact by correspondence or telephone we used the most recent of the following, where applicable, as the last known date of follow up: date of discharge from the Royal New Zealand Navy, the hospital discharge date (where it was known that an admission had occurred), date of application for driver's licence or car registration, or date of emigration (where known).

The information on mortality and incidence of cancer was then compared with that from other sources. Dr Gulbransen's survey had identified 24 subjects eligible for our study who were reported to have died during 1957-87; all of these were confirmed by our follow up. He had also identified a further seven subjects with cancer; six of these were identified in the search of the cancer registry, and a recheck of the cancer registry verified that the other subject reported to have cancer was not in the registry (the registration was therefore not included in the study). The Returned Services Association's survey identified seven eligible subjects who were reported to be deceased; all seven deaths were confirmed by our follow up. It also reported five cases of cancer in eligible subjects; all were identified in the search of the cancer registry. A further 104 subjects had been classified as deceased in Ministry of Defence records; of these, six were found to be alive and three had died overseas. Of the remaining 95 men, 92 were identified as deceased; a recheck of the death records verified that the three other men had not been recorded as having died during 1957-87. Finally, 32 respondents reported that their cancer had been diagnosed during 1957-87; of these, 25 had already been identified in the search of the cancer registry, and a recheck of the cancer registry confirmed that the remaining seven men with cancer were not listed in the registry (these included one control with Hodgkin's disease). 


\section{DATA ANALYSIS}

Test participants were followed up from the date of the first test in which they participated. Controls were followed up from 15 May 1957; the date of discharge if this occurred before 15 May 1957; or the date of enlistment if this occurred after 15 May 1957. Follow up ceased on the date of death, the date of emigration, or 31 December 1987 (in those who were alive on that date). For those subjects of unknown vital state, follow up ceased on the last date on which vital state was known. For the analysis of incidence of cancer the last date of follow up was the date of cancer registration for those who had developed cancer.

The number of expected deaths was calculated with a computer program package ${ }^{6}$ using New Zealand mortality and cancer incidence rates during 1957-87 broken down by age (in five year groupings) and calendar period (in five year groupings). Cancer incidence was not available for 1967 , and we assumed that the rates were the same as for 1962-66. Similarly, the incidence was not available for 1983-7, and we assumed that the rates were the same as for 1978-82.

For each outcome the number of observed deaths or cases of cancer were divided by the expected number to yield the standardised mortality ratio or standardised incidence ratio. The relative risk for each outcome was then estimated by taking the ratios of the standardised mortality ratios in the test participants and controls. Problems may arise from comparing standardised mortality ratios in this manner ${ }^{7}$ as these ratios are not mutually standardised, but this theoretical problem is trivial when, as in the current study, the age and calendar period distributions of the two groups are similar (table II). In fact, there was very little confounding by age and calendar period, and the crude (non-standardised) relative risks were virtually identical to the standardised relative risks. Similarly, adjustment for various potential confounders, such as rank, year of enlistment, year of discharge, length of service, and length of follow up, was not necessary as the two groups were very similar with respect to these factors.

Confidence intervals were calculated by the method of Ederer and Mantel ${ }^{8}$ with the aid of a computer program developed by Gardner and Altman. ${ }^{9} \mathbf{P}$ values were calculated using the uncorrected MantelHaenszel $\chi^{2}$ adapted for person-time data, ${ }^{710}$ but the mid-p form of Fisher's exact test ${ }^{7}$ was used for the haematological cancer and leukaemia findings because of the small numbers included. As in the previous British study ${ }^{11}$ we were specifically interested in testing the hypothesis that mortality and incidence of cancer were greater in the test participants than in the controls. Thus one tailed $p$ values and $90 \%$ confidence intervals were used throughout.

\section{Results}

At the end of follow up $50(10 \%)$ of the test participants and $171(11 \%)$ of the controls were of unknown vital state (table III). A more appropriate estimate of the completeness of follow up is given by the ratio of the total person years of follow up actually achieved to that of the total number of person years that theoretically could have been achieved if, for those of unknown vital state, follow up had continued until 31 December 1987.'2 For the test participants there were 13923 person years of follow up, compared with a total of 14883 person years that theoretically could have been achieved: a completeness of follow up of $94 \%$. The corresponding figures for the controls are 38937 and 42598 person years: a completeness of follow up of $91 \%$.

Table IV shows that mortality in the controls was close to that expected on the basis of national mortality but that mortality was slightly higher among the test participants. Consequently, the relative risk was also slightly raised (relative risk $1 \cdot 08,90 \%$ confidence interval 0.85 to $1.38, p=0.29$ ). There was a slight deficit for causes of death other than cancer in both the test participants and the controls, and the relative risk was $0.96(0 \cdot 71$ to $1 \cdot 29, \mathrm{p}=0 \cdot 59)$.

The findings for cancer are less straightforward. Both the test participants and the controls had raised death rates for cancer, but the increased risk was greater in the test participants, yielding a relative risk of $1 \cdot 38(0 \cdot 90$ to $2 \cdot 10, \mathrm{p}=0 \cdot 09)$. Table $\mathrm{V}$ shows that the relative risk for non-haematological cancers was $1 \cdot 14$ $(0.69$ to $1.83, \mathrm{p}=0.31)$

The two sites of strong a priori interest were multiple myeloma and leukaemia, which both belong to the general category of haematological cancers (Hodgkin's disease, non-Hodgkin's lymphoma, multiple myeloma, and leukaemia). Overall, seven test participants died of haematological cancers compared with six controls, yielding a relative risk of $3.25(1 \cdot 12$ to $9 \cdot 64, p=0.02)$. This excess risk was mainly due to four deaths from leukaemia among the test participants (relative risk $5 \cdot 58,1.04$ to $41 \cdot 6, p=0.03$ ). There were no deaths from multiple myeloma among the test participants, but the expected number was only $0 \cdot 2$. In fact, one multiple myeloma was identified in a test participant, but this was diagnosed in 1988 (after follow up had ceased), and death occurred in 1989.

In addition to those who died of cancer, seven test participants and 29 controls were registered as having cancer (table VI). The relative risk for cancer was $1 \cdot 12$ $(0.78$ to $1.60, \mathrm{p}=0.29)$ and that for non-haematological cancer was $1.01(0.67$ to $1.50, p=0.48)$. Seven test participants and 10 controls had haematological cancers (relative risk $1.94,0 \cdot 74$ to $4 \cdot 84, p=0 \cdot 10$ ). No additional leukaemia registrations were identified, and the relative risk was thus virtually unchanged (relative risk $5 \cdot 51,1 \cdot 03$ to $41 \cdot 1, \mathrm{p}=0 \cdot 03$ ).

The two deaths from non-Hodgkin's lymphoma among test participants had been coded as a mycosis fungoides and a malignant histiocytosis. The one death and one registration for non-Hodgkin's lymphoma among the controls were both reticulosarcomas. Of the six deaths from leukaemia, four were confirmed by examination of the relevant hospital notes and two were confirmed by contacting the deceased patient's

TABLE IV - Number of observed and expected deaths and standardised mortality ratios (SMRs) by general cause of death categories

\begin{tabular}{|c|c|c|c|c|c|c|c|c|c|}
\hline \multirow[b]{2}{*}{ Cause of death } & \multirow[b]{2}{*}{ ICD categories } & \multicolumn{3}{|c|}{ Test participants } & \multicolumn{3}{|c|}{ Controls } & \multirow[b]{2}{*}{ Relative risk } & \multirow{2}{*}{$\begin{array}{l}90 \% \text { Confidence } \\
\text { interval }\end{array}$} \\
\hline & & Observed & Expected & SMR & Observed & Expected & SMR & & \\
\hline Cancer & $140-209$ & 26 & $14 \cdot 4$ & $1 \cdot 80$ & 52 & $40 \cdot 0$ & $1 \cdot 30$ & $1 \cdot 38$ & $0 \cdot 90$ to $2 \cdot 10$ \\
\hline $\begin{array}{l}\text { Circulatory } \\
\text { Respiratory } \\
\text { Digestive } \\
\text { Genitourinary } \\
\text { Accidents, etc } \\
\text { Other causes } \\
\end{array}$ & $\begin{array}{l}390-459 \\
460-519 \\
520-579 \\
580-629 \\
800-999\end{array}$ & $\begin{array}{r}21 \\
2 \\
2 \\
2 \\
14 \\
3 \\
\end{array}$ & $\begin{array}{r}24 \cdot 9 \\
3.5 \\
1 \cdot 7 \\
0 \cdot 6 \\
11 \cdot 3 \\
4 \cdot 3 \\
\end{array}$ & $\begin{array}{l}0.84 \\
0.57 \\
1.18 \\
3.17 \\
1.24 \\
0.69 \\
\end{array}$ & $\begin{array}{r}58 \\
8 \\
13 \\
1 \\
38 \\
9\end{array}$ & $\begin{array}{r}68 \cdot 7 \\
9 \cdot 6 \\
4 \cdot 7 \\
1 \cdot 8 \\
31 \cdot 5 \\
12 \cdot 1 \\
\end{array}$ & $\begin{array}{l}0 \cdot 84 \\
0 \cdot 84 \\
2 \cdot 77 \\
0 \cdot 57 \\
1 \cdot 21 \\
0 \cdot 74 \\
\end{array}$ & $\begin{array}{l}1.00 \\
0.69 \\
0.43 \\
5.56 \\
1.03 \\
0.93\end{array}$ & $\begin{array}{l}0.63 \text { to } 1.55 \\
0.11 \text { to } 2.82 \\
0.07 \text { to } 1.58 \\
0.44 \text { to } 162 \\
0.58 \text { to } 1.77 \\
0.22 \text { to } 3.11\end{array}$ \\
\hline Total non-cancer & & 44 & $46 \cdot 4$ & 0.95 & 127 & $128 \cdot 6$ & 0.99 & $0 \cdot 96$ & 0.71 to 1.29 \\
\hline Total deaths & & 70 & $60 \cdot 9$ & $1 \cdot 15$ & 179 & $168 \cdot 6$ & $1 \cdot 06$ & $1 \cdot 08$ & 0.85 to 1.38 \\
\hline
\end{tabular}




\begin{tabular}{|c|c|c|c|c|c|c|c|c|c|}
\hline \multirow[b]{2}{*}{ Site of cancer } & \multirow[b]{2}{*}{ ICD categories } & \multicolumn{3}{|c|}{ Test participants } & \multicolumn{3}{|c|}{ Controls } & \multirow[b]{2}{*}{ Relative risk } & \multirow{2}{*}{$\begin{array}{c}90 \% \text { Confidence } \\
\text { interval }\end{array}$} \\
\hline & & Observed & Expected & SMR & Observed & Expected & SMR & & \\
\hline \multicolumn{10}{|c|}{ Non-haematological cancers } \\
\hline Cheek or pharynx & $140-149$ & 2 & 0.4 & $5 \cdot 26^{\circ}$ & 1 & $1 \cdot 0$ & 0.96 & $5 \cdot 47$ & 0.43 to 159 \\
\hline Oesophagus & 150 & 1 & 0.4 & 2.56 & 1 & $1 \cdot 1$ & 0.93 & $2 \cdot 77$ & 0.07 to 107 \\
\hline Stomach & 151 & $i$ & $0 \cdot 9$ & $1 \cdot 11$ & 6 & $2 \cdot 5$ & $2 \cdot 42$ & $0 \cdot 46$ & 0.02 to 2.99 \\
\hline Small intestine & 152 & 0 & $0 \cdot 1$ & $0 \cdot 00$ & 0 & $0 \cdot 2$ & $0 \cdot 00$ & & \\
\hline Colon & 153 & 2 & 1.5 & $1 \cdot 32$ & 6 & $4 \cdot 2$ & $1 \cdot 42$ & 0.93 & $0 \cdot 14$ to $4 \cdot 18$ \\
\hline Rectum & 154 & 1 & $0 \cdot 9$ & 1.06 & 3 & $2 \cdot 6$ & $1 \cdot 16$ & 0.92 & 0.04108 .33 \\
\hline Larynx & 161 & 0 & $0 \cdot 2$ & $0 \cdot 00$ & 0 & $0 \cdot 4$ & $0 \cdot 00$ & & \\
\hline Lung & 162 & 4 & $3 \cdot 8$ & 1.05 & 13 & $10 \cdot 5$ & $1 \cdot 23$ & 0.85 & $0 \cdot 26 \div 02 \cdot 36$ \\
\hline Bone & 170 & 0 & $0 \cdot 1$ & 0.00 & 0 & $0 \cdot 2$ & 0.00 & & \\
\hline Connective tissue & 171 & 0 & $0 \cdot 1$ & $0 \cdot 00$ & 0 & $0 \cdot 3$ & 0.00 & & \\
\hline Prostate & 185 & 1 & $0 \cdot 4$ & $2 \cdot 27$ & 3 & $1 \cdot 2$ & $2 \cdot 54$ & 0.89 & 0.03 to 8.11 \\
\hline Testis & 186 & 0 & $0 \cdot 3$ & $0 \cdot 00$ & 1 & $0 \cdot 8$ & 1.33 & 0.00 & 0.00 to $52 \cdot 8$ \\
\hline Bladder & 188 & 1 & $0 \cdot 2$ & $4 \cdot 36$ & 0 & $0 \cdot 6$ & 0.00 & & \\
\hline Kidney & 189 & 2 & $0 \cdot 4$ & 5.00 & 3 & $1 \cdot 1$ & 2.73 & 1.83 & 0.23 to 11.8 \\
\hline Brain or nervous sustem & 191,192 & 1 & $0 \cdot 8$ & $1 \cdot 30$ & 2 & $2 \cdot 1$ & 0.94 & 1.39 & 0.05 to 17.8 \\
\hline Other sites & & 3 & $2 \cdot 6$ & $1 \cdot 15$ & 7 & $7 \cdot 3$ & 0.96 & $1 \cdot 19$ & $0 \cdot 27$ to $4 \cdot 28$ \\
\hline Total & & 19 & $13 \cdot 1$ & $1 \cdot 46$ & 46 & $36 \cdot 1$ & $1 \cdot 27$ & $1 \cdot 14$ & 0.69 to 1.83 \\
\hline \multicolumn{10}{|c|}{ Haematological cancers } \\
\hline $\begin{array}{l}\text { Non-Hodgkin's } \\
\text { lymphoma }\end{array}$ & 200,202 & 2 & $0 \cdot 4$ & $5 \cdot 13$ & 1 & $1 \cdot 1$ & 0.92 & $5 \cdot 59$ & 0.44 to 163 \\
\hline Hodgkin's discase & 201 & 1 & $0 \cdot 2$ & 4.35 & 1 & 0.6 & 1.56 & $2 \cdot 78$ & 0.07 to 107 \\
\hline Multiple mveloma & 203 & 0 & $0 \cdot 2$ & 0.00 & 2 & $0 \cdot 5$ & $3 \cdot 85$ & 0.00 & 0.00 to $9 \cdot 50$ \\
\hline Leukaemia & $204-208$ & 4 & $0 \cdot 6$ & $7 \cdot 02$ & 2 & $1 \cdot 6$ & $1 \cdot 26$ & $5 \cdot 58$ & $1 \cdot 04$ to $41 \cdot 6$ \\
\hline Total & & 7 & $1 \cdot 4$ & $5 \cdot 07$ & 6 & $3 \cdot 8$ & 1.56 & $3 \cdot 25$ & $1 \cdot 12$ to 9.64 \\
\hline Total of all cancers & & 26 & $14 \cdot 4$ & $1 \cdot 80$ & 52 & $40 \cdot 0$ & $1 \cdot 30$ & 1.38 & $0 \cdot 90$ to $2 \cdot 10$ \\
\hline
\end{tabular}

physician. The four leukaemias in test participants included a chronic lymphocytic leukaemia, an acute myeloid leukaemia, a chronic myeloid leukaemia, and an acute unspecified leukaemia; the two leukaemias in controls were an acute lymphocytic leukaemia and a chronic myeloid leukaemia.

Subgroup analyses were of limited value because of the small numbers included.' The only information that was available on surrogates for radiation exposure was the number of tests attended: three of the test participants with leukaemia had attended one to three tests $(0 \cdot 3$ expected, standardised incidence ratio $10 \cdot 21)$; one had attended four to six tests $(0.4$ expected, standardised incidence ratio 2.64), and none had attended seven or more tests $(0.0$ expected). The corresponding numbers for the total number of haematologic cancers were four $(0 \cdot 9,4 \cdot 26)$, three $(1 \cdot 2$, $2 \cdot 49)$, and zero $(0 \cdot 1)$.

\section{Discussion}

In the protocol for this study we noted that the number of deaths and cancer registrations would be relatively small, and that the findings should be interpreted in light of the much larger study of British armed forces personnel who took part in the same series of tests. "It should be emphasised, however, that Operation Grapple represented only nine of the tests in the series of 21 tests covered by the British study; thus the exposures may not be directly comparable.

In the British study the most noteworthy finding was that mortality from multiple myeloma and leukaemia in test participants was only slightly higher than that expected on the basis of national death rates (standardised mortality ratios of $1 \cdot 11$ and 1.13 respectively) but was substantially higher than in controls. Thus the relative risks were definitely raised for both neoplasms (relative risks of infinity and 3.45 respectively). The authors noted that these findings were of particular interest because leukaemia is the type of cancer with a consistently increased incidence in populations exposed to relatively high doses of ionising radiation. " Furthermore, multiple myeloma is the one type of cancer for which a dose related association has been shown in two large groups of workers in the nuclear industry. ${ }^{13}$ The authors noted that the increases for multiple myeloma and leukaemia "cannot therefore be lightly dismissed as chance findings," but there were considerable problems of interpretation as the excess risks for these two types of cancer were TABLE VI - Incidence of cancer, expected incidence, and standardised incidence ratios (SIRs) by site

\begin{tabular}{|c|c|c|c|c|c|c|c|c|c|}
\hline \multirow[b]{2}{*}{ Site of cancer } & \multirow[b]{2}{*}{ ICD categories } & \multicolumn{3}{|c|}{ Test participants } & \multicolumn{3}{|c|}{ Controls } & \multirow[b]{2}{*}{ Relative risk } & \multirow{2}{*}{$\begin{array}{c}90 \% \text { Confidence } \\
\text { interval }\end{array}$} \\
\hline & & Observed & Expected & SIR & Observed & Expected & SIR & & \\
\hline \multicolumn{10}{|c|}{ Non-haematological cancers } \\
\hline Stomach & 151 & 1 & $1 \cdot 2$ & $0 \cdot 81$ & 10 & $3 \cdot 4$ & $2 \cdot 94$ & $0 \cdot 27$ & 0.01 to 1.57 \\
\hline Colon & 153 & 3 & $2 \cdot 9$ & 1.05 & 6 & $8 \cdot 0$ & 0.76 & $1 \cdot 39$ & $0 \cdot 30$ to $5 \cdot 26$ \\
\hline Rectum & 154 & 2 & 1.8 & $1 \cdot 12$ & 4 & $5 \cdot 0$ & 0.81 & $1 \cdot 38$ & 0.19 to $7 \cdot 43$ \\
\hline Lung & 162 & 6 & $4 \cdot 6$ & $1 \cdot 30$ & 16 & $12 \cdot 6$ & $1 \cdot 27$ & $1 \cdot 03$ & $0 \cdot 40$ to $2 \cdot 42$ \\
\hline Connective tissue & 171 & 0 & $0 \cdot 3$ & 0.00 & 0 & 0.9 & 0.00 & & \\
\hline Testis & 186 & 0 & 1.0 & $0 \cdot 00$ & 3 & $2 \cdot 7$ & $1 \cdot 12$ & $0 \cdot 00$ & 0.00 to $4 \cdot 80$ \\
\hline Bladder & 188 & 2 & 1.0 & 1.98 & 0 & $2 \cdot 8$ & 0.00 & & \\
\hline Thyroid & 193 & 0 & $0 \cdot 2$ & $0 \cdot 00$ & 0 & $0 \cdot 5$ & 0.00 & & \\
\hline Endocrine & 194 & 0 & $0 \cdot 1$ & $0 \cdot 00$ & 0 & $0 \cdot 2$ & 0.00 & & \\
\hline Other sites & & 12 & $9 \cdot 9$ & $1 \cdot 21$ & 32 & $27 \cdot 3$ & $1 \cdot 17$ & $1 \cdot 03$ & 0.55101 .87 \\
\hline Total & & 26 & $22 \cdot 9$ & $1 \cdot 13$ & 71 & $63 \cdot 2$ & $1 \cdot 12$ & $1 \cdot 01$ & 0.67 to 1.50 \\
\hline \multicolumn{10}{|c|}{ Haematological cancers } \\
\hline $\begin{array}{l}\text { Non-Hodgkin's } \\
\text { lymphoma }\end{array}$ & 200,202 & 2 & $0 \cdot 8$ & $2 \cdot 44$ & 2 & $2 \cdot 3$ & 0.88 & $2 \cdot 77$ & \\
\hline Hodgkin's disease & 201 & 1 & 0.5 & 1.96 & 2 & 1.4 & 1.41 & 1.39 & 0.05 to $17 \cdot 8$ \\
\hline Multiple myeloma & 203 & 0 & $0 \cdot 3$ & 0.00 & 4 & 0.7 & 5.56 & $0 \cdot 00$ & 0.00 to 3.09 \\
\hline Leukaemia & $204-208$ & 4 & 0.7 & $5 \cdot 48$ & 2 & $2 \cdot 0$ & $1 \cdot 00$ & $5 \cdot 51$ & 1.03 to 41.1 \\
\hline Total & & 7 & $2 \cdot 3$ & $3 \cdot 02$ & 10 & $6 \cdot 4$ & 1.56 & 1.94 & 0.74 to 4.84 \\
\hline Total of all cancers & & 33 & $25 \cdot 2$ & $1 \cdot 31$ & 81 & $69 \cdot 6$ & $1 \cdot 16$ & $1 \cdot 12$ & 0.78 to 1.60 \\
\hline
\end{tabular}


primarily due to decreased risks in the controls, and the excesses were not characteristic of men with measured doses or even of men present at the time of the tests. The authors therefore cautiously concluded that "there may well have been small hazards of both diseases associated with participation in the programme but that this has not been proved." Professor Martin Gardner, in an accompanying editorial, was prepared to go further and stated that "the preferred conclusion so far must surely be that some leukaemias, and probably multiple myelomas, have resulted from radiation exposure during the tests." ${ }_{1+}$

In the current study, total mortality was greater in the test participants than in the controls, but the increase in risk was very small. Cancer mortality was raised in both groups, possibly due to the high rates of smoking (table II), but the increase was greater in the test participants. The relative risk of death from nonhaematological cancers was $1 \cdot 14$, and the relative risk for incidence was 1.01 . Thus there is little evidence of an increased risk for non-haematological cancers in the current study, and there was actually a slight deficit of these cancers in the British study.

The most striking finding in the current study is the excess risk of haematological cancers in the test participants, which was largely due to the occurrence of four deaths from leukaemia. The findings for other specific haematological cancers are difficult to interpret because the numbers are so small. In particular, the expected number of multiple myelomas in test participants was only $0 \cdot 3$. Lymphomas (that is, Hodgkin's disease and non-Hodgkin's lymphoma) have been found in excess in atomic bomb survivors and other populations exposed to high doses of radiation, ${ }^{15}$ but the evidence is less persuasive for exposure to low doses, ${ }^{16}$ and there was actually a slight deficit of non-Hodgkin's lymphomas in the British study." Furthermore, some of the lymphomas found in our study are not known to be strongly radiogenic ${ }^{16}$ and some reviewers have questioned whether Hodgkin's disease is in fact radiogenic. ${ }^{1 ?}$

Leukaemia was of prime interest in the current study. The findings of the British study were difficult to interpret as they were primarily due to a deficit of leukaemia in the controls, but this problem does not apply to our study. The four deaths from leukaemia in test participants included one death from chronic lymphocytic leukaemia, which has not been associated with exposure to either high doses or low doses of radiation. A further problem of interpretation is that three of the leukaemias in the test participants (as well as both leukaemias in the controls) occurred more than 25 years after the tests, and only one occurred less than 15 years after the tests. The usual "latency period" between exposure and diagnosis of leukaemias caused by ionising radiation is two to 25 years. ${ }^{15}$ Longer latency periods have, however, been observed in Hiroshima survivors aged less than 35 at time of exposure $^{18}$ and might in fact be expected if exposure were due to ingestion or inhalation of long lived radionuclides." Thus the leukaemia findings cannot be dismissed simply on the basis that some leukaemias were diagnosed more than 25 years after exposure occurred.

Apart from chance, there are three other possible explanations for the findings for leukaemia and other haematological cancers: they could reflect either bias, confounding, or a causal relation.

The loss of some $10 \%$ of men from follow up is the least satisfactory aspect of this study. This reflects the difficulties of conducting follow up studies in New Zealand, where there is no national population register or identification number, and when there has recently been significant emigration to Australia and other countries. Nevertheless, the biases that could hypothetically result from incomplete follow up (or from incomplete identification of study subjects) would be expected to affect all causes of death, rather than just haematological cancers. Thus it seems unlikely that such hypothetical biases could account for our findings. The possibility of diagnostic bias (that is, that leukaemias may have been more readily diagnosed in test participants because of the well known association between exposure to radiation and leukaemia) cannot be excluded, but there is no evidence that this occurred.

It is also unlikely that the findings for haematological cancers are entirely due to confounding because the test participants and controls seem very similar in most respects (table II), and it is difficult to think of relevant risk factors that could have differed greatly between the two groups.

No information is currently publicly available on the doses of gamma radiation received by the Royal New Zealand Navy participants in the test programme, but published information on the British participants in the same programme suggests that the gamma radiation doses they received were very small." However, no data are available on neutron radiation exposure, and no data are available on internal radiation exposure due to inhalation or ingestion of radioactive particles. The latter may be relevant as the Pukaki and Rotoiti visited Christmas Island after the tests, and it has been hypothesised that rainout into the lagoon and concentration in the food chain could have occurred. ${ }^{19}$ The possibility of significant exposure through inhalation or ingestion has previously been raised for United States Army participants in the Smoky nuclear weapons tests ${ }^{20}$; they experienced an increased incidence of leukaemia with relative risks similar to those reported here. Beebe suggested that there was almost certainly biologically significant exposure to radio active isotopes through the food chain, and there may have been other internal exposure to radiation..$^{21}$ Thus although currently available data indicate that the Royal New Zcaland Navy personnel in Operation Grapple probably received very low doses of gamma radiation, the possibility cannot be excluded that there could have been significant external exposure to neutron radiation or internal exposure due to inhalation or ingestion. There are currently no publicly available data to confirm or refute these hypotheses.

In summary, the findings presented here indicate that New Zealand participants in the British nuclear weapons test programme have not experienced any detectable increase in risks of death for causes other than cancer, and there is little evidence of an increased risk for non-haematological cancers. These findings are reassuring and indicate that there has not been a detectable effect on overall life expectancy from participation in the programme. Some leukaemias, however, and possibly some other haematological cancers may have resulted from participation in the nuclear weapons test programme. These findings should be interpreted with caution as they are based on small numbers. If these findings are not merely due to chance then they are most likely to be causal rather than due to bias or confounding. Perhaps the strongest reason for concluding that the leukaemia findings may reflect a causal relation is that a similar excess risk was found in the previously published study of British participants in the same nuclear weapons testing programme.

We are particularly grateful to Dr Malcolm McNamara and $\mathrm{Mr}$ John Crawford from the Ministry of Defence, who provided excellent cooperation throughout the study. $\mathrm{Mr}$ Crawford had previously done a great deal of work that laid 
the foundations of the current study, and we are grateful for his willingness to make these data available to us. We are also grateful to Mr Glen Mandahl from the New Zealand Returned Services Association and Dr Graham Gulbransen for their support and excellent cooperation. We thank Professor Sir Richard Doll, Dr Elisabeth Cardis, Dr Sarah Darby, and Dr Ichiro Kawachi for their comments on the draft report; the staff at the National Health Statistics Centre and New Zealand Cancer Registry and at the Justice Department; Regina Winkelmann of the International Agency for Research on Cancer for supplying data on New Zealand mortality and incidence of cancer; and Trevor Williams, department of community health, Wellington School of Medicine, for his clerical and administrative help with this study. Finally, Jackie Auld and Gail de Boer thank the Director General of Health for granting permission to publish.

1 Crawford JAB. The involvement of the Royal New Zealand Navy in the British nuclear testing programmes of 1957 and 1958. Wellington: Ministry of Defence, 1989 .

2 Pearce NE, Prior IAM, Methven D, et al. Mortality and cancer incidence in New Zealand participants in United Kingdom nuclear weapons tests in the Pacific. Wellington: Department of Community Health, Wellington School of Medicine, 1990.

4 World Health Organisation. Manual of the international statistical classification of diseases, injuries, and causes of death. 9th Revision, 1975. Geneva: WHO, 1977.

5 Foster FH. The New Zealand Cancer Registry. N Z Med F 1977;86:341-3.

6 Coleman M, Douglas A, Hermon C, et al. Cohort study analysis with a FORTRAN computer program. Int $\mathcal{F}$ Epidemiol 1986;15:134-7.
7 Rothman KJ. Modern epidemiologv. Boston: Little, Brown, 1986.

8 Ederer $\mathrm{F}$, Mantel N. Confidence limits on the ratio of two Poisson variables. Am f Epidemiol 1974;100:165-7.

9 Gardner MJ, Altman DG. Statistics with confidence. London: British Medical Journal, 1989.

10 Mantel N, Haenszel W. Statistical aspects of the analysis of data from retrospective studies of disease. 7 NCI 1959;22:719-48.

11 Darby SC, Kendall GM, Fell TP, et al. A summary of mortality and incidence of cancer in men from the United Kingdom who participated in the United Kingdom's atmospheric nuclear weapons tests and experimental programmes. Br Med J 1988;296:332-8.

12 Checkoway H, Pearce NE, Crawford-Brown DG. Research methods in occupational epidemiology. New York: Oxford University Press, 1989.

13 Cardis E. Ionizing radiation and electromagnetic fields. In: Higginson J, Muir CS, Munoz N, Sheridan M, eds. The epidemiologv and causes of human cancer. Cambridge: Cambridge University Press, 1990.

14 Gardner M. Cancer among participants in tests of British nuclear weapons. BrMed f 1988;296:309-10.

15 Darby SC, Nakashima E, Kato H. A parallel analysis of cancer mortality among atomic bomb survivors and patients with ankylosing spondylitis given X-ray therapy. $7 N C I$ 1985; $75: 1-21$.

16 Greene MH. Non-Hodgkin's lymphoma and mycosis fungoides. In: Schottenfeld D, Fraumeni JF, eds. Cancer epidemiology and prevention. Philadelphia: W B Saunders, 1982 .

17 Boice JD, Land CE. Ionizing radiation. In: Schottenfeld D, Fraumeni JF, eds Cancer epidemiology and prevention. Philadelphia: W B Saunders, 1982.

18 Beebe GW. A methodologic assessment of radiation epidemiology studies. Health Phys 1984;46:745-62.

19 Gulbransen G. New Zealand radiation veterans: Christmas Island 1957-58 N Z General Practice 1989;2:11-15.

20 Caldwell GG, Kelley D, Zack M, Falk H, Heath CW. Mortality and cancer frequency among military nuclear test (Smoky) participants, 1957 through 1979. FAMA 1983;250:620-4.

21 Beebe GW. Ionizing radiation and health. Am Scientist 1982;70:35-44.

(Accepted 10 April 1990)

\title{
Prospective study of human parvovirus (B19) infection in pregnancy
}

\author{
Public Health Laboratory Service Working Party on Fifth Disease
}

\begin{abstract}
Objective-To determine the fetal infection rate and outcome of pregnancy among women who acquire infection with human parvovirus $(B 19)$ in the antenatal period.
\end{abstract}

Design-Prospective study of infected pregnancies till time of delivery or abortion with virological investigation of fetuses, neonates, and 1 year old infants.

Setting-England and Wales during 1985-8.

Patients - 190 Pregnant women with serologically confirmed B19 infection in pregnancy, their fetuses, neonates, and 1 year old infants.

Results-Of 186 mothers who elected to go to term, $156(84 \%)$ delivered a normal baby. Follow up of 114 of these infants to the age of 1 year disclosed no appreciable abnormalities, although $27 \mathrm{had}$ serological evidence of intrauterine infection. The overall fetal loss rate ( 30 cases; $16 \%$ ) was similar to that in an uninfected antenatal sample (unmatched), but there was a pronounced excess of fetal loss in the second trimester in the B19 infected mothers $(11.8 \%$; $95 \%$ confidence interval $6 \cdot 8 \%$ to $17 \cdot 8 \%$ ). Based on virological findings in the aborted fetuses the risk of fetal death due to B19 in an infected pregnancy was estimated to be $9 \%$. The transplacental transmission rate was estimated to be $33 \%$.

Conclusions-Most women with B19 infection in pregnancy had a satisfactory outcome, but there was nevertheless a substantial risk of fetal loss in the second trimester. In view of the absence to date of any evidence of damage to babies who survive maternal infection therapeutic termination of pregnancy is not indicated.

\section{Introduction}

Human parvovirus (B19), first discovered in 1975 in serum from healthy blood donors, ${ }^{1}$ is now known to be the cause of transient aplastic crisis in patients with chronic haemolytic anaemias ${ }^{2}$ and of erythema infectiosum (fifth disease). ${ }^{3}$ In 1984 the first case reports of B19 having an adverse effect in pregnancy were published..$^{+5}$ At least 20 fetal deaths have been described in which fetal tissues contained B19 DNA. ${ }^{6}$ The virus replicates in erythroid progenitor cells, ${ }^{7}$ which may cause profound anaemia and congestive cardiac failure in the fetus.

Fifth disease is a common childhood exanthem and the recognition that its causative agent was potentially embryopathic provoked considerable public and professional concern. ${ }^{89}$ This concern, however, was based either on evidence from small numbers of subjects or on case reports and series in which an adverse outcome of pregnancy had led to the retrospective diagnosis of B19 infection, thus providing a biased estimate of risk. ${ }^{+5}{ }^{10-14} \mathrm{We}$ therefore began a prospective investigation of a larger population of women with B19 infection in pregnancy to determine $(a)$ the risk of adverse fetal outcome, $(b)$ the transplacental transmission rate, and $(c)$ the neonatal and longer term outcome. Long term follow up of the infants is not yet complete, but because of the public health implications we report here our initial results.

\section{Subjects and methods}

Study population and recruitment - The study population comprised pregnant women who were investigated prospectively, usually by their general practitioners (for example, because of a rash or contact with erythema infectiosum), and who had B19 infection confirmed by the presence of B19 IgM. Patients with B19 infection who had been investigated because of a fetal death were excluded. Recruitment took place between January 1985 and June 1988. Cases were ascertained when the result for each eligible subject was sent to the study base by one of the five B19 reference laboratories in England. 